\title{
Relapse of Multibacillary Leprosy Treated with Rifampicin and Ofloxacin: A Case Report
}

\section{Santosa Basuki* and Martina Rahmi}

Department of Dermatology and Venereology, Brawijaya University, Dr. Saiful Anwar General Hospital, Malang, Indonesia

*Corresponding author: Santosa Basuki, Department of Dermatology and Venereology, Brawijaya University, Dr. Saiful Anwar General Hospital, Malang, Indonesia, Tel: +62 0341-340991; E-mail: sant911@yahoo.com

Received date: November 03, 2017; Accepted date: December 02, 2017; Published date: December 08, 2017

Copyright: (C) 2017 Basuki S, et al. This is an open-access article distributed under the terms of the Creative Commons Attribution License, which permits unrestricted use, distribution, and reproduction in any medium, provided the original author and source are credited.

\begin{abstract}
Introduction: Despite the dramatic success of the MDT by WHO regimens, a newer generation such as Ofloxacin displayed very promising bactericidal activity and in combination with Rifampicin by far is the highly bactericidal drug against $\mathrm{M}$. leprae.

Case summary: A 38 year old Javanese man presented with relapsed leprosy after a 14 month course of WHO MDT. He complained persisted lesions all over his body lasting 1 year and several well demarcated erythematous and hyperpigmented plaques were observed. There were sensory impairment on some lesions and thickening of nerve on extremities. Leprosy was diagnosed in 2014 and after he completed WHO-MDT for 1 year, his BI was found to be $3+$ and $\mathrm{Ml}$ of $10 \%$. A skin biopsy revealed borderline lepromatous and upgrading reaction. He was started on re-treatment MBMDT for two months but lesions persist and skin smear increased, showed a BI 5+ with MI of $60 \%$. He was commenced on daily $600 \mathrm{mg}$ rifampicin, $400 \mathrm{mg}$ ofloxacin and $500 \mathrm{mg}$ aspirin three times daily for six months. The patient completed the treatment and his lesions regressed.
\end{abstract}

Conclusion: This case highlights therapeutic efficacy of Rifampicin and Ofloxacin in producing clinical improvement and bacterial killing. Additionally it resurrects the use of aspirin to treat type 1 reaction.

Keywords: Multibacillary; Leprosy; Relapse; Rifampicin; Ofloxacin

\section{Introduction}

Ofloxacin displayed very promising bactericidal activity against $M$. leprae in a murine model and 4 weeks of treatment with of ofloxacin daily produced remarkable clinical improvement and killed at least $99.99 \%$ of $M$. leprae bacilli in leprosy patients, it was thought that, in combination with rifampin, by far the most bactericidal drug against $M$. leprae. Ofloxacin might provide the potential to increase the effectiveness and to shorten the duration of anti-leprosy chemotherapy, and that it was likely that all Rifampicin resistant mutants in an untreated leprosy patient could be eliminated with an ofloxacincontaining regimen [1]. We reported multibacillary leprosy relapse and treated with rifampicin and ofloxacin.

\section{Case Report}

A 38 year old Javanese man presented to our dermatology and venereology clinic reported with red patches over various part of his body on face, neck, trunk, arms, palms and legs. The lesions were non pruritic and unpainful, developed since one year ago, began as small red patches on anterior chest wall and left forearm. He also complained about partial loss of sensation and tingling on his upper extremities (left forearm and hands) and lower extremities (feet). He also experienced fever at some time since eight months ago, associated with redness on patches.

A history revealed that he first noticed the tingling and numbness on his feet and hands started six years ago, and two years ago he had visited neurology clinic and was consulted to Dermatology and Venereology department before diagnosed as multibacillary morbus hansen. Patient was also consulted to Ear, Nose and Throat department for his nasal stuffiness and department of rehabilitation medicine for his hands and feet abnormality. He was put on MBMDT (WHO regimen) since November 2013 which he completed in December 2014. The bacteriological examination was performed and showed solid bacilli so he was given retreatment of MDTMB without dapsone due to low hemoglobin along with aspirin orally due to his reversal reaction. After two months above treatment, reddish patches become still persisted and were thickened. Slit skin smear was repeated showed higher bacteriological index (BI) than latest one. There were no families or friends suffering from similar ailment.

Dermatological examination showed lesions on the face, trunk, arms and legs in the form of erythematous and some hyperpigmented, multiple, wrinkly and shiny plaques, well demarcated, and without scales. Soft-firm over normal-edematous area without tenderness area on palpation (Figure 1). There was madarosis on right eyebrow and in both earlobes were infiltrate was seen. Patient had claw hands deformity and toe bent on left foot (Figure 2). He had thickened both right and left ulnaris and common peroneal nerves but no paresthesia. Examination of sensitivity includes pain, touch, and temperature test were obtained anesthesia lesion of erythematous plaques on left lower arm and chest. There were also impairment of pain, touch and temperature sensation on palms and soles. Motoric examination revealed muscle strength of abduction of little fingers and right great toe grip were reduced.

Patient looked as moderately ill with blood pressure $110 / 80 \mathrm{~mm} \mathrm{Hg}$, pulse rate was 84 times per minute, respiration rates 20 times per 
Page 2 of 3

minute and body temperature was $37^{\circ} \mathrm{C}$. There was neither anemic conjunctiva nor icterus. There were no lagopthalmus, nose deformity, gynecomastia or testicular enlargement. Heart and lung sound were normal; liver and spleen were not palpable. There was no edema in his extremities. No lymph node enlargement

Slit skin smear showed acid-fast bacilli (AFB) with bacteriological index $(\mathrm{BI})$ of $5+$ and morphological index $(\mathrm{MI})=60 \%$. Biopsy was taken from a representative anesthetic lesion. The results of the histopathology examination showed normal epidermis and granulomata inflammation on the dermis. There was Grenz zone with foamy histiocytes within granulomas, few epitheloid, some Langerhans giant cells and lymphocytes infiltrate within granuloma (Figure 1). The feature suggested borderline lepromatous multi-bacillary leprosy with upgrading (type 1) reaction.

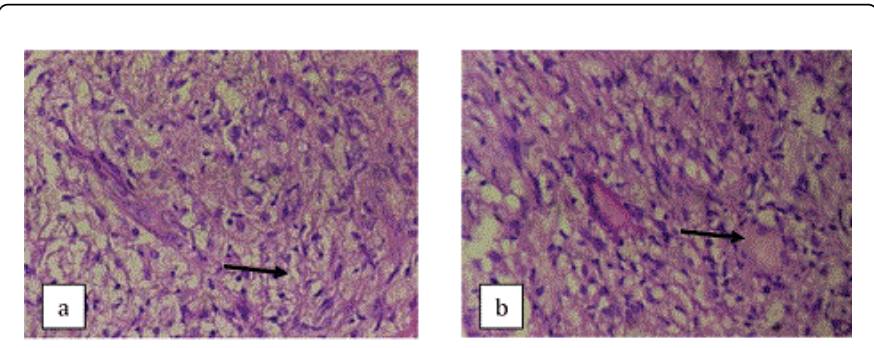

Figure 1: Histopathology examination. Foamy histiocytes within granulomas (arrow) (a) and some langerhans giant cells (arrow) (b) (Hematoxilin Eosin, 400x magnification)

Hematological findings included complete blood count, AST and ALT, ureum were within normal except there were elevated Erythrocyte Sedimentation Rate (ESR) $40 \mathrm{~mm} / \mathrm{h}$ and raised creatinine level $(1.28 \mathrm{mg} \mathrm{mg} / \mathrm{dl})$. Consultation to Internal department was performed due to the result and they suggested continuing medication, to keep fluid balance by drinking no less than eight glasses a day and avoid nephrotoxic drugs.
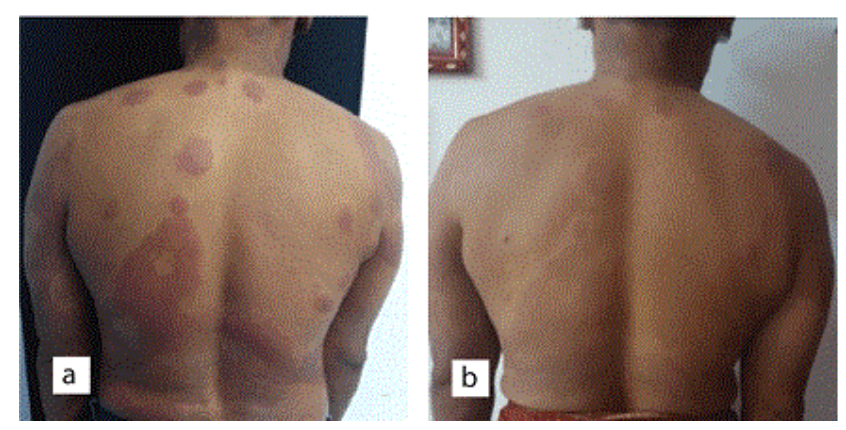

Figure 2: After treatment of rifampicin, ofloxacin and aspirin for 6 months (a) Reduction of redness and swelling compared to before treatment (b) at trunkus anterior and posterior.

Based on history taking, dermatology, physical, bacteriology and histopathology examination, patient was diagnosed with multibacillary leprosy relapse and reversal reaction. He was commenced on daily $600 \mathrm{mg}$ rifampicin and $400 \mathrm{mg}$ ofloxacin along with aspirin $3 \times$ $500 \mathrm{mg}$ orally and was kept on regular follow up. After 6 months of follow up, Slit Skin Smear examination showed BI+5 adn MI was 20\%. Additionally, redness and swelling of plaque subsided (Figure 2).

\section{Discussion}

Patient is a 38 year old man neither presented with non-pruritic nor painful erythematous and some hyperpigmented, multiple, wrinkly and shiny plaques, well demarcated, soft-firm over normal-edematous area without tenderness area on palpation on the face, trunk, arms and legs. He had thickened both right and left ulnaris and common peroneal posterior nerves but no paresthesia. Examination of sensitivity includes pain, touch, and temperature test were obtained anesthesia lesion of erythematous plaques on left lower arm and chest. There were also impairment of pain, touch and temperature sensation on palms and soles. Motoric examination revealed muscle strength of abduction of little fingers and right great toe grip were reduced. The patient reported here had persisting BI and MI, at the end of which a course of MDT MB, BI 5+ and MI $10 \%$ and two months after, the index was increasing to $\mathrm{BI}+5$ and $\mathrm{MI} 60 \%$.

The treatment of leprosy, compared with other infectious diseases, is unique in terms of the fixed dose and duration of regimens and also in terms of the definition of "cure". The definition of "relapse" can be understood only in the context of the definition of "cure". As of 1995, WHO recommends 1 year of MDT for MB patients (12 pulses in 18 months) and 6 months (six pulses in 9 months) for PB patients. For operational purposes, once a patient receives adequate chemotherapy, he is considered "cured" [2].

Histopathologically, relapse in multi-bacillary leprosy are characterized in the early stage of relapse by emergence of foci of spindle shaped macrophages with granular, eosinophilic cytoplasm along with small foci of persisting foamy histiocytes and solid staining AFB in these patients who have not completely become smear negative [3]. The result of our patient's biopsy confirmed leprosy spectrum. Histopathology also revealed he had an upgrading reaction, indicating an increase in cell-mediated immunity [4]. However, our patient here never had skin biopsy done earlier so we could not determine the changes in histopathology feature.

In the light of this, there is a possibility that this patient could have resistance or be a slow responder and therefore we decided to use the alternate regimen of daily Rifampicin and Ofloxacin (and Asprin) which resulted in a good clinical improvement of the lesions, as well as a drop in BI/MI and a subsidence in Type 1 Reaction.

Combinations of daily rifampin and newer bactericidal drugs (minocycline, clarithromycin, and fluorquinolones), each having been demonstrated to be more active than dapsone and clofazimine, appear to be reasonable treatments [5]. Fluoroquinolones are active against $M$. leprae by inhibiting DNA gyrase and inhibiting DNA replication and transcription. Although not considered primary therapy in most instances, fluoroquinolones, such as moxifloxacin and ofloxacin, remain an important option for treating Hansen's disease, especially in patients with intolerance, resistance, or clinical failure to primary therapy [5].

Our patient was planned to re-treatment for his relapse of MDT MB according recommended treatment regimen for multi-bacilary with a relapse (Table 1), however the smear didn't show satisfactory result after two months of treatment so the patient was given combination of rifampicin and newer bactericidal drug ofloxacin daily for six months. 
Citation: Basuki S, Rahmi M (2017) Relapse of Multibacillary Leprosy Treated with Rifampicin and Ofloxacin: A Case Report. J Dermatol Dis 4:

Page 3 of 3

After treatment completion, Bacterial Index and Morphological Index were decreased.

\begin{tabular}{|c|c|c|}
\hline Resistance & Scenario & Treatment \\
\hline $\begin{array}{l}\text { Relapse with M. leprae } \\
\text { sensitive to all standard } \\
\text { drugs }\end{array}$ & $\begin{array}{l}\text { Relapse after a course of } \\
\text { MB-MDT }\end{array}$ & $\begin{array}{l}\text { Retreatment with WHO } \\
\text { MDT depending on the } \\
\text { type of disease (PB or } \\
\text { MB-MDT) }\end{array}$ \\
\hline $\begin{array}{l}\text { Relapse with dapsone- } \\
\text { resistant M. leprae }\end{array}$ & $\begin{array}{l}\text { Release after previous } \\
\text { "cure" with dapsone } \\
\text { monotherapy }\end{array}$ & Standard WHO MDT \\
\hline $\begin{array}{l}\text { Relapse with rifampicin- } \\
\text { resistant or rifampicin- } \\
\text { and dapsone-resistant M. } \\
\text { leprae }\end{array}$ & $\begin{array}{l}\text { Primary or secondary } \\
\text { dapsone-resistant MB } \\
\text { cases who received } \\
\text { standard WHO MB-MDT } \\
\text { but did not take their } \\
\text { clofazimine } \\
\text { equivalent to rifampicin } \\
\text { monotherapy) }\end{array}$ & $\begin{array}{l}\text { Clofazimine } 50 \mathrm{mg} \text { daily } \\
\text { for } 24 \text { months plus two } \\
\text { of the following drugs } \\
\text { for } 6 \text { months: ofloxacin } \\
400 \mathrm{mg} \text { daily or } \\
\text { minocycline } 100 \mathrm{mg} \\
\text { daily or clarithromycin } \\
500 \mathrm{mg} \text { daily, followed } \\
\text { by: ofloxaacin } 400 \mathrm{mg} \\
\text { daily or minocycline } 100 \\
\text { mg daily for the } \\
\text { remaining } 18 \text { months }\end{array}$ \\
\hline
\end{tabular}

Table 1: Recommended treatment regimens [6].

Regimens containing ofloxacin are found to increase the likelihood of reactions [4]. Although reaction occurred in this patient, it was mild and was controlled with a course of aspirin $3 \times 500 \mathrm{mg}$. However, further follow up need to be carried out to closely monitor the frequency and severity of reactions and neuritis in patient.

\section{Conclusion}

We reported a 38 years old man with multibacillary leprosy relapse. He was commenced on $600 \mathrm{mg}$ rifampicin, $400 \mathrm{mg}$ ofloxacin daily and
$500 \mathrm{mg}$ aspirin three times daily. After 6 months of follow up, After 6 months of follow up, Slit Skin Smear examination showed BI +5 and MI was 20\%. Redness and swelling of Type 1 reaction lesions additionally subsided. The report is important in that it highlights the value of using Oflaxacin along with Rifampicin as an alternate drug combination where dapsone cannot be used because of hypersensitivity and where Clofazimine cannot be used because of the skin pigmentation. Additionally it resurrects the use of Aspirin to treat Type 1 Reaction.

\section{References}

1. Ji B, Jamet P, Sow S, Perani EG, Traore I, et al. (1997) High relapse rate among lepromatous leprosy patients treated with rifampin plus ofloxacin daily for 4 weeks. Antimicrob Agents Chemother, pp: 1953-1956.

2. Kaimal S, Thappa DM (2010) Relapse in leprosy. In: Hemanta Kumar Kar, Bushan Kumar editor. IAL Textbook of Leprosy. 1st ed. New Delhi, Jitendar P vij., pp: 483-491.

3. Singh A, Weng X, Nath I (2011) Skin biopsy in leprosy. In : Uday Khopkar editor. Skin Biopsy - Perspectives. InTech. 5: 73-86.

4. Suneetha S (2001) Histological resolution and bacterial clearance with pulse rom therapy in borderline lepromatous leprosy: Correspondence. International Journal of Leprosy, pp: 53-54.

5. Gelber RH (1998) Another view of the therapy of leprosy. Antimicrob Agents Chemother 998: 3334-3336.

6. Matrat S, Petrella S, Cambau E, Sougakoff W, Jarlier V, et al. (2007) Expression and purification of an active form of the Mycobacterium leprae DNA gyrase and its inhibition by quinolones. Antimicrob Agents Chemother 51: 1643-1648. 